2015

13

Working Paper

INSTHUTO DE POLfHICAS Y BIENES PÚBLIGOS [IPP]

THE

INTERNATIONALISATION OF RESEARCH INSTITUTES

Laura Cruz-Castro

Koen Jonkers

Luis Sanz-Menéndez

CSIC
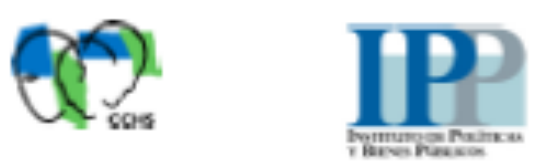


\section{INSTITUTO DE POLÍTICAS Y BIENES PÚBICOS - CSIC}

Copyright $@ 2015$. Laura Cruz-Castro, Koen Jonkers \& Luis Sanz-Menéndez. All rights reserved.

Instituto de Políticas y Bienes Públicos

Consejo Superior de Investigaciones Científicas

C/ Albasanz, 26-28

28037 Madrid (España)

Tel: +34916022300

Fax: +34 913045710

http://www.ipp.csic.es

How to quote or cite this document:

Cruz-Castro, L, Jonkers, K.. \& Sanz-Menéndez, L. (2015). The internationalisation of research institutes. Instituto de Políticas y Bienes Públicas (IPP) CSIC, Working Paper. 2015-13.

Available at: digital.csic.es 


\title{
The internationalisation of research institutes
}

\author{
Laura Cruz-Castro ${ }^{1}$, Koen Jonkers ${ }^{2}$ and Luis Sanz-Menéndez ${ }^{1}$ \\ CSIC Institute of Public Goods and Policies
}

Citation: Cruz-Castro, Laura, Jonkers, Koen and Sanz-Menéndez, Luis (2015). "The Internationalisation of Research Institutes”. In Linda Wedlin and Maria Nedeva (eds.). Towards European Science. Dynamics and Policy of an Evolving European Research Space (pp. 175-198). Cheltenham: Edward Elgar, 2015. ISBN: 978178254550 7. DOI 10.4337/9781782545514

\section{INTRODUCTION}

Governments continue to be key players in research, despite the significance of private investments. Governments' direct funding, regulations and incentives are essential factors and mechanisms in steering and funding research (OECD 2011b). However countries differ in the basic features and the institutional arrangements of their Public Sector Research (PSR) (Senker 2000; Whitley 2003) and in the extent to which universities and non-university research organizations are key research performing actors in PSR.

While in the US, and some other countries, research universities have become the central institution in PSR, in many continental European countries, in addition to the traditional government laboratories, a different type of "non-university" Public Research Organization (PRO) is also a central actor of the PSR. In countries like Germany, France, Spain, Italy, Poland, Slovak Republic, Hungary, Romania and others, a specific type of institution, public research centres, have complemented, and historically at some time replaced, the research functions of the universities.

\footnotetext{
${ }^{1}$ Funding from the Ministry of Economic Affairs and Competitiveness (grant CSO2011-29431) is acknowledged.

${ }^{2}$ This chapter was mostly prepared when this author was still based at the CSIC institute for Public Goods and Policies. The information and views set out in this chapter do not necessarily reflect the opinion of the second author's current employer, the European Commission. The EC does not guarantee the accuracy of the data included in this study. Neither the EC nor any person acting on its behalf may be held responsible for the use which may be made of the information contained herein.
} 
In recent years in all European countries, PSR has been undergoing important changes. The first one is, that universities have gradually become the major research performing actor in almost all European public research (Paradeise et al. 2009; Nedeva 2013), with increasing competition and environmental pressures for the PRO. Secondly, PSR have experienced a changing balance between block and project funding (Lepori et al. 2007; OECD 2011b), the increased use of performance based funding mechanisms (OECD 2010; Hicks 2012; Whitley 2008) and, in Europe, the growing role of EU funding. Finally, the PRO has been subject to significant reforms and transformations, including deregulation and transfer of ownership from governments to other actors (Boden et al. 2006). PROs are estimated to be spending over 40 per cent of the total public research funds allocated by governments to research in the EU. ${ }^{3}$

While the transformations of universities have attracted a lot of attention, the focus on the changes in PRO has been more limited (Cox et al. 2001). Besides the concerns about the effects of privatisation and new public management (Boden et al. 2004) or the adaptation responses to changes in funding (Sanz-Menendez and CruzCastro 2003), most of the contributions have addressed a specific type of PRO (for example, Mission Oriented Research, the National Laboratories (Crow and Bozeman 1998) or the Research Technology Organizations (RTO) (Sharif and Baark 2011), while the issue of the role of European research policy in changes has been mostly overlooked. In fact, while PROs have traditionally been considered as very responsive to national governments' demands, despite their relevance in terms of public expenditure, no significant efforts have been made to better understand the impact of the European research policy and the emergence of a new space for research on the functioning, structures and strategies of PROs. In this chapter we are interested in how public research organizations address internationalisation pressures and Europeanisation dynamics.

Whereas internationalisation of research (with a focus on individual research collaboration and, more recently, on researcher mobility) has been widely analysed, we do not know that much about internationalisation processes and strategies at the organizational level of research institutes. The conditions under which organizational actors engage and invest resources in international activities are understudied. The

${ }^{3}$ http://ec.europa.eu/research/era/areas/urpo/urpo en.htm; http://www.earto.eu/fileadmin/content/04 Newsletter/RPO Study Comments.pdf. 
structure of the PSR (Senker 2000) and the organizational features of PRO (Whitley 2008) are intervening variables that condition the internationalisation process; here we will try to build an analytical framework to provide a better understanding of the role of key organizational attributes of PRO in the internationalisation process.

Firms have attracted most of the attention in the scholarly analysis of strategic organizational behaviour related to internationalisation and globalisation of $R \& D$ activities (Gassmann and von Zedtwitz 1999; von Zedtwitz and Gassmann 2002); additionally, the literature on research collaboration presents evidence on the exponential growth of international co-authorship as an indicator of this trend (Katz and Martin 1997). Literature on higher education institutions also provides us evidence about the increasing role of international competition for talent, students and academics, and the attempts to develop an overseas presence by more and more universities (Bartell 2003; Stromquist 2007).

Despite the existence of some literature analysing the PRO, very few authors have specifically addressed the internationalisation process, its features and consequences for different types of research institutes (Ebersberger and Edler 2009; Jonkers and Cruz-Castro 2011; Van den Besselaar et al. 2012). Even in the very few analyses of mostly descriptive nature (Berger and Hoffer 2011; Edler et al. 2012) there is some evidence of an increase in non-nationally based operations of PRO growing in parallel with the internationalisation or globalisation of their "national systems".

The aim of this chapter is to understand how different types of research institutes (PRO) engage in processes of internationalisation, paying attention to the interplay between EU research policy and research organizations. The chapter is organized as follows. In the next section we review the drivers of internationalisation and build up the analytical framework on the role of some key features of PRO in the internationalisation process. After that, we revise the emergence and changes of the EU research policy as part of the changing environment of PRO and describe some Europeanisation developments. We then apply our classificatory framework to analyse the internationalisation capabilities of four types of PRO that differ in specific organizational characteristics which have direct implications for the ways in which the PRO internationalise. The chapter ends with some concluding remarks. 


\section{CONCEPTS, DRIVERS AND ANALYTICAL FRAMEWORK}

This chapter is based on the premise that organizational differences generate variations in internationalisation processes, and that those very features will also influence the ways in which the process of internationalisation emerges and evolves. To analyse these processes we propose a framework for understanding the internationalisation processes of PROs based on organizational and institutional theory; this approach provides us with theoretical grounds for addressing the key issue of the relationship between the organization and its environment(s) and how organizations internationalise in two distinct ways: responsive vs. strategic. In this section we set up the framework for the analysis; we begin with some definitions, followed by the identification of the main drivers of internationalisation, and finally we present our typology of PRO according to some key organizational attributes.

By internationalisation we understand a process of increasing involvement in international (non-nationally based) operations and actions by the PRO, its sub-units or its employees and an increasing openness of the PRO to 'non-national' influences, with the effect of transforming the attributes of the organization and of modifying its resource dependence features (for example, funding composition). It may also be understood as different forms of commitment with regards to resources to be invested or acquired from abroad outside the traditional national markets or sources of resources. In the literature on Europeanisation, the concept has been mainly used in analyses of changes in national policy making in response to the emergence of a European level of policy making (Olsen 2002). Here we understand Europeanisation as consisting of processes of growth in the interaction of PRO with research performing actors in other EU member-states and EU level actors (policy makers, funding agencies and political actors) through various forms of collaboration, competition, adaptation and influence.

The means through which the PRO can exert its potentiality for internationalisation are a) material: through decisions on the internal distribution of its resources, b) institutional: through political influence and negotiation and c) discursive: through mission statements and discussion of goals/aims/ambitions it can attempt to interactively engage in setting an agenda for future action. In doing so, the PRO can, on the one hand, contribute to the socialisation of its researchers and stimulate them to engage in particular forms of behaviour, such as collaboration and competition for 
resources at the European level. On the other hand, it can engage in setting an external discourse that may have some influence on decisions at the national and European level.

Most of the evidence about the internationalisation of scientific research often considered it to have been driven primarily through individual level self-organized networks of scientists. This, however, is not the only aspect of the internationalisation/Europeanisation process. Organizational level strategies can also play a role. Here, strategic internationalisation understood as the commitment of resources at the organizational level is different from encouraging or rewarding individual 'spontaneous' international collaborations.

The process of PRO internationalisation can be understood as an adaptation to technological, economic, political and cultural change (Slipersaeter and Aksnes 2012). Much of the empirical analysis and theory development regarding internationalization has referred to firms and their R\&D functioning. Dominant views in business and management studies have adopted a theoretical approach that emphasises responses to reduce uncertainty in a changing environment, with a focus on rational calculations of the benefits and costs of the process; very few studies have made the attempt of developing organizational models for understanding internationalisation processes (e.g. Malhotra and Hinings 2010). In organizational theory, a stream of literature (Drori et al. 2003) has addressed the processes of globalisation and internationalisation from the perspective of diffusion dynamics and adoption of new normative models. From this view, PRO, like firms, may engage in learning/imitation to implement the structures and strategies developed by their domestic and foreign counterparts to engage in internationalisation. However, it is our contention that management and economic approaches do not fully capture the variety of strategic drivers of public and semi-public research organizations to engage in internationalisation.

We consider that the main driving goal of organizational behaviour is preservation/maintenance and potential expansion. This motivation is strongly tied up with access to resources. Both firms and PROs internationalise as a way of accessing markets, clients and resources. PROs develop internationalisation mainly as a way to reduce resource dependency, to increase the diversification of their resources or expand their resource base. PROs may also have other objectives, including their organizational/political missions, societal impact and reputation, visibility or search for excellence. Their need for material resources refers mainly to funding but also to the 
maintenance and expansion of their scientific and technological human capital (Bozeman et al. 2001). Although accessing markets may be a driver for PROs too, it is important to acknowledge that PROs operate in different types of spaces. Firstly, the research space/research system in which they get their public and private funding, and secondly, the research field in which they (also) disseminate and valorise their products and through which they access other resources: new knowledge, feedback and so on (Nedeva 2013). Like individual researchers, PRO are at the interface of the two domains. The PRO's need for resources is not restricted to the material (funding) but also includes cognitive and institutional resources.

For PROs the goal of internationalisation/Europeanisation has traditionally been linked to the search for new funding sources (diversification and reducing the dependence of traditional sources), though increasing their international reputation which can be tied to the accumulation of cognitive, institutional and symbolic resources also plays an important role. International funding has been mostly competitive (especially at the EU level) although there are instances of international block grant funding, for example in the cases of international cooperative research facilities. However, apart from funding and the increasing costs of research, the drivers for internationalisation of PRO have multiplied over the last decade (see also Boekholdt et al. 2009). Related to the increasing costs of (large-scale) research comes the need of most PROs to engage in the sharing of costs and risks. Internationalisation can also provide PROs with access to non-financial resources including infrastructure, human resources recruitment, data and partners with complementary capabilities and resources.

Additional to expanding and accessing resources, a second driver for internationalisation is related to the changing dynamics of research, the changing demands made by the principals of PRO (for example, to enhance their contribution to innovation activities) and the environmental changes in the research space of PROs, such as the emergence of research funding agencies and the growing role of research universities in many countries. The compounded effect of these dynamics have stimulated and enabled PROs to increase their links with other actors in their national innovation systems. PROs may also find these other actors outside their national research space. Related to this, a third driver, namely the increasing commercialisation of research outputs in global markets, is also relevant. 
Several additional drivers can be identified. The globalisation of scientific fields and the associated motivation to increase the visibility and impact of their research, combined with the increasing role of transnational research funding as well as the emergence of new actors at the European level and the policies made at this level. National policies and institutional changes can also provide important motivations for expanding their activities to the European level. Interacting with PROs in other countries can be a source of institutional learning and can lead to the formation of alliances that can increase the PROs' potential to influence the development of their national and European research space too. Finally, related to policies and institutional dynamics but also tied to technological developments, are the increasing opportunities for mobility and long-distance communication that can enable PROs and their researchers to engage in long-distance collaboration, competition and international recruitment.

All PROs have been exposed to these environmental dynamics and yet we see diversity in the ways and extent to which they are internationalising. While recent studies on internationalisation have drawn the attention to various factors that are likely to cause variations in the process, we need to understand more systematically why such variations occur. A missing element in current research on internationalisation/Europeanisation of PRO is an understanding of how the organizational characteristics of a PRO may influence its internationalisation process.

It has become traditional to identify three types of PRO: government laboratories, academic, and research and technology organizations (Arnold et al. 2010; OECD 2011a). Based on their diverse nature, here we distinguish four organization (ideal) types of PRO: the Public Research Centre (PRC) (academic or basic research), the Mission Oriented Research Centre (MOC) (applied and use-oriented), the Research Technology Organization (RTO) (commercially-oriented) and the Independent Research Institute (IRI) (Pasteur quadrant type of research (Stokes 1997)) (OECD 2011c).

In order to address the questions of what would be the expected responses of PRO to the pressures for internationalisation, we advance an analytical framework to interpret organizational variation. Based on diverse contributions from the organizational, institutional and sociology of science literature (March 1994; Whitley 2003) we have identified a few attributes of the different types of organizations that are 
likely to condition the forms and dynamics of the internationalization process: a) the degree of external autonomy and resource dependence of the organization - in terms of funding, human resources, access to external knowledge, for instance - and the associated degree of autonomy and discretion over resources; b) the type of internal authority structure that characterises the functioning of the organization; and c) the nature of the knowledge production, dissemination and use processes. The forms adopted (modes of operation of internationalisation that can be more or less strategic) will also be influenced by these three basic organizational attributes; consequently we expect to observe different levels of attention and resource commitment for internationalisation by the different PROs over time.

Building on these attributes, we developed a table that classifies the different ideal types of PRO according to (a) their external autonomy and (b) their internal authority, the two attributes that shape the opportunities of PRO management to develop strategic internationalisation.

able 1 Classification of (ideal types) PRO according to attributes a (external autonomy) and b (internal authority)

\begin{tabular}{|l|l|l|l|}
\hline \multicolumn{2}{|c|}{ PRO Management } & \multicolumn{2}{c|}{ Internal authority } \\
\cline { 3 - 4 } \multicolumn{2}{|c|}{} & + & - \\
\hline External autonomy & + & RTO & IRI \\
\cline { 2 - 4 } & - & $M O C$ & PRC \\
\hline
\end{tabular}

Source: Authors

Additionally, the type of knowledge produced by RTO and MOC tends to be applied in nature and to either be commercialised or offered to other stakeholders/principals/clients (including governmental actors). In the case of PRC the main knowledge products tend to be fundamental in nature and be published in academic journals, although they may also engage in applied research, consultancy work, patenting and so on. IRI aim to produce knowledge products in Pasteur's quadrant (scientific excellence and potential for application). They will mainly publish in academic journals as well, but potentially produce relatively more of the other types of knowledge products (mainly patents) than PRC (Martinez et al. 2013).

There are limits for strategic action that the PRO has to engage in an interactive way (through adaptation and interaction) with its changing environment. Here we build on the notion of organizational actorhood (Krücken and Meier 2006; Whitley 2008). 
The concept of strategic action emphasises external autonomy and internal integration. For research institutes to develop internationalisation as an independent organizational goal they need to have some autonomy with respect to the state, but also with respect to the scientific elites. Whether and how managers/directors can use authority and incentives to coordinate and direct initiatives towards internationalisation, not necessarily in a hierarchical way, also influence their capacity to engage strategically with this process.

It is thus important to note that we are dealing with two levels (or units of analysis) that we could identify with internationalisation: the individuals/sub-units and the organization as a whole. From the literature on research collaboration we find that the levels of internationalization of different sub-units in organizations are very diverse and probably conditioned by the disciplines or research areas (Nedeva 2013). Also related to the attributes identified above, internationalisation processes thus depend on field dynamics that occur at the subunit level.

Later in this chapter we apply this framework to analyse the internationalisation processes of four types of PRO that differ in specific organizational characteristics that have direct implications for the ways in which the PRO internationalise. More specifically, we should be able to generate plausible predictions about the ways in which research institutes allocate their own resources (investments, researchers and other staff, opening up of facilities, and so on) to improve their production and expand their activities (in some cases following clients) or search for international resources (such as clients, funding, and incoming researchers) to continue their internal production.

\section{EUROPEANISATION OF THE PRO EXTERNAL ENVIRONMENT: THE ROLE OF THE EU RESEARCH POLICY}

In the last 30 to 50 years research policy ${ }^{4}$ developed at the European level has modified the environment of all research actors in Europe, including PRO. As in the

\footnotetext{
${ }^{4}$ The first time when a specific chapter on research policy appeared in the treaty was in the Single European Act of 1987 (http://eurlex.europa.eu/LexUriServ/LexUriServ.do?uri=OJ:L:1987:169:FULL:EN:PDF, article 130f-130q). There had been earlier starts of European research policies going back to at least the third treaty which allowed for the launch of some research programs in priority areas in the 1960s and 1970s. Both the Euratom treaty
} 
case of universities, PRO interactions with European research policy develop at two levels: on the one hand, at the level of teams and researchers (sub-units within the organizations) who interact directly, in the context of research funding, with the policy instruments and, on the other hand, with the strategies that PRO managers develop either to take advantage of, or to shape, European research policy. However, we should not take for granted that policy interventions at the European level produce organizational effects, because the primary environment of most research organizations continues to be national or local.

The aim is to highlight that, in the context of a policy historically shaped by direct implementation and distributive functions, recently complemented by regulatory and coordination activities (Banchoff 2002), the main research policy instruments have been focused on researchers and teams, more than on research institutions. European research policies have traditionally been built on the principle of improving conditions for research, with a strong emphasis on collaboration and networking (Guzzetti 1995). The traditional research and innovation support activities of the EU have had a focus on joint research collaboration and improving European competitiveness through financing mainly transnational research collaboration and mobility of researchers (SanzMenéndez and Borrás 2001); in this context the Europeanisation of research organizations has been an indirect effect of increasing links and networks. We believe that European research policy has, in general terms, been ill-equipped to produce strong structural effects at the level of the research organizations, which have continued mainly to respond to national pressures; in this context most of the impact on organizations has been through indirect effects.

When building expectations about the influence of the European policies in the Europeanisation of PRO, it is important to take into account the way research organizations are funded and their internal authority structures. Despite their steady growth, the EC contribution to the overall European budget on R\&D is about 16 per cent while national sources account for 84 per cent of public civil research and development (R\&D) budget in the European Union (European Commission 2011: 79). However, the EU's share of competitively allocated project funding is considerably higher and those additional resources have attracted the interest of researchers and 
research organizations. Nonetheless, the main policy environment of PROs across Europe continues to be the national one and nationally-based funding remains by far the most important source of resources for them.

Together with large multilateral research facilities in particular fields, like the CERN or the EMBL, the Framework Programmes (FP) institutionalised European research policy from the 1980s onwards, through funding research collaboration in specific fields (see chapter 2 of this volume). The FPs developed with the rationale of fostering collaboration among member countries in particular programmatic areas, and with an emphasis on cross-national networks. The main actors were the researchers and teams and not the organizations. As a funding source highly dependent and contingent on micro dynamics, this type of instrument could hardly become a strong driver of organizational change. ${ }^{5}$

Likewise, although very competitive, mobility programmes such as Marie Curie actions were targeted at individuals as well, with marginal institutional control on the inflows, and, especially, outflows. In this context, PROs have been highly dependent on the researchers' international networks and their interest and decisions to apply to funding calls. Thus the capacity of those instruments to generate structural and strategic effects at the level of the organization is limited, except in the case of institutions that effectively value international mobility and grant raising capacities in their evaluation, recruitment and promotion systems.

Some argue that in the 1990 s the policy networks of research organizations, researchers and administrators which had formed around and relied on the existing FP instruments resisted change that could have led to further European integration (Banchoff 2002: 3). The launching of the Lisbon Strategy and the European Research Area (ERA) initiative represented an attempt to redefine the objectives and targets of EU research policy (see chapter 3 of this volume). The development of the idea of ERA was structured around three main objectives: to increase integration, to reduce fragmentation and to create a strong European science base. One of the basic ideas of the ERA was the creation of an internal market for research within which knowledge would circulate freely and some efforts have been made during the last decade to remove barriers against researcher mobility: in 2005 the council adopted the scientific

\footnotetext{
${ }^{5}$ In a case study of La Sapienza, Primeri and Reale (2012) argued that FP participation by individual researchers had limited impact on the Europeanisation of the organization as a whole.
} 
visa package. ${ }^{6}$ In 2005 the Commission recommended the European Charter for Researchers and the Code of Conduct for their recruitment. ${ }^{7}$ On a voluntary basis, by 2008 more than 150 institutions had signed their interest in implementing the principles of the Code of Conduct. Meanwhile the EC has also attempted to redirect funding to promote further integration: Networks of Excellence and Integrative Projects were two new instruments of the 6th Framework Programme. As regards the actor level, Edler (2003: 118) argued in 2003 that only if European research organizations and other national actors believed in the added value of long-term European large scale, largely self-organized projects, would the ERA materialise beyond the logic of extra money. Overall, Chou (2012) argues, the evolution of the EU research policy has mainly been characterised by gradual institutional change through "layering" rather than through "displacement", in the sense that new rules have been progressively adopted in coexistence with the old ones .

The set-up of the European Research Council, (ERC), in 2007, signalled a new, complementary, approach based on scientist-driven research, frontier knowledge and excellence, rather than on the traditional mission-oriented competitiveness (see chapters 2 and 4 of this volume). One of the explicit objectives of the ERC as regards research organizations was to develop their research strategies and priorities to become global players in research. Recent empirical evidence suggests that ERC grants strengthen the position of excellent researchers within their organizations, by binding the granted funds to the specific activities proposed by the principal investigators. Research groups are built around lines of research that may or may not be part of the strategic planning of the management of the organization (Edler et al. 2012: 39). There thus appears to be an internal contradiction between the normative pressures on the organizations to provide the conditions to attract and retain grantees (autonomy and support) and the binding of resources and development of autonomous trajectories that this implies. The limited actorhood of some major kinds of $\mathrm{PRO}^{8}$ helps to explain why in some cases,

\footnotetext{
${ }^{6}$ The scientific visa package consists of one directive http://eurlex.europa.eu/LexUriServ/LexUriServ.do?uri=CELEX:32005L0071:EN:NOT and two recommendations: http://eur-lex.europa.eu/LexUriServ/LexUriServ.do?uri=CELEX:32005H0762:EN:NOT and http://eurlex.europa.eu/LexUriServ/LexUriServ.do?uri=CELEX:32005H0761:EN:NOT. Denmark and the UK have opted out of the directive which is binding for other countries. In March 2013 the European Commission proposed a new visa directive.

${ }^{7}$ http://ec.europa.eu/euraxess/index.cfm/rights/recommendation .

${ }^{8}$ This applies, essentially, to the academic ones at a medium level of research endowments and autonomy.
} 
additional European money does not add to organizational authority over resources. Despite this tension research institutions may use the ERC as a motivation and justification for making internal reforms. Edler et al.'s study thus suggests that the emergence of this new funding mechanism on the European landscape can have a positive effect on the internationalisation/ Europeanisation of this type of PRO (Edler et al. 2012; Edler et al. 2014; see also Nedeva et al. 2012: 7).

Current European level science policy still combines cooperation and competition, scientific excellence and political goals (Nedeva and Stampfer 2012). In theory, increasing competition should provide a push towards internationalisation. PRO, universities and researchers are supposed to compete for researchers, students and research funds. International collaboration is seen as a means to stay at the frontier of knowledge creation and gain reputation, which is a self-reinforcing process. And often, internationalisation is perceived as a quality indicator per se.

The empirical descriptive study of Europeanisation has traditionally been based on input and output indicators (e.g. Van den Besselaar et al. 2012), reflecting activities that can develop as the result of either bottom-up activities of individual researchers or research units, or as the result of top-down policies.

While reflecting Europeanisation, however, these indicators do not necessarily reflect the type of organizational change that is of interest in this chapter. For example, a large share of European funding in a PRO's budget can in some cases be the product of the sum of multiple initiatives by individual researchers, the result of the strategic actions of the PRO management, or of the effect of the actions and demands of policy makers which fund, steer and exploit the abilities of the PRO. A small share of European funding in a PRO's budget may be a reflection of a lack of incentives for individual researchers to compete/collaborate internationally, of a lack of competitiveness/abilities/means of individual researchers or the organization as a whole, of a continued reliance on national sources in the absence of the previous three strategies, and/or of the limited freedom given to the PRO leadership by its principal to engage with actors outside the national system. While an increase in the budget share indicates some Europeanisation/internationalisation it does not necessarily imply strategic Europeanisation/internationalisation at the organizational level.

A second group of developments can be associated more clearly with a process of organizational change related to Europeanisation/internationalisation of the PRO as it 
refers to changes in organizational structures and strategies; these are, among others, access to resources or sharing (joint infrastructures), and the set-up of facilities abroad.

Other organizational changes, including changes in structures governing the recruitment, evaluation and promotion of researchers and the allocation of human and capital resources more generally, reflect the strategic aim to engage in internationalisation/Europeanisation, when they are aimed, for example at attracting European funding or excellence strategies. This can also include the use of foreign experts in the evaluation of personnel and organizations.

PROs may establish representations at international organizations (including the European Institutions), engage in international or Europe-wide networks to influence European policies/strategies that affect them (for example, EARTO, ALLEA, ESF, EUROHORCS), or engage in ad hoc joint initiatives aimed at the EU policy level.

In order to study organizational change and strategic internationalisation one would need to develop indicators capable of capturing processes. For example: open recruitment practices, or the existence of organizational structures for the support of Europeanisation, the presence of Europeanisation objectives in strategic plans or internationalisation criteria in evaluation procedures, or the existence of incentives for the researchers or managers to internationalise.

A question remains about the right policies and instruments to promote the transformation of local actors into European and global ones not necessarily through setting up facilities abroad but through servicing globally. The EMBL and the European University Institute are examples of European funded research organizations playing globally and operating under rules, which make them distinctive in comparison to most European universities and PRO. But there are also instances of nationally funded organizations that have been able to evolve into this type of global actor and change some of their functioning rules (for example, the German Max Planck Society (MPG) or the French National Center for Scientific Research (CNRS)). Since national funding is likely to remain the principal funding source of existing PRO, the interplay between national funding and the change of organizational objectives and internal management towards internationalisation is of greatest importance. This does not imply that there is no room for European level policies to impact on this process. On the contrary, as we will conclude later, the combination of legislative and non-legislative measures might 
trigger the commitment to Europeanisation goals at the national level, even for organizations that will continue to be primarily funded by national sources.

\section{INTERNATIONALISATION OF RESEARCH INSTITUTES AS STRATEGIC ADAPTATION}

In this section we apply the framework developed above (variations in external autonomy and internal authority) to characterise the internationalisation of the different types of PRO identified (PRC, MOC, RTO and IRI) and make some plausible predictions based on their strategic capacities and constraints.

Regarding external autonomy, a first relevant condition for strategic action at the PRO level is related to the amount of resources that organizations are entitled to manage in a discretionary way. If they lack such a control and in the absence of slack resources they can devote to particular goals, it is very difficult for the PRO to even think about internationalisation as a real strategic option beyond "rhetorical discourses" and implementation designs based on delegation to researchers (Edler et al. 2011); in general, poor research organizations are unlikely to internationalise and PROs under financial strain are likely to reduce their internationalisation activities. A case study of the internationalisation of a North American university highlighted the potential conflict between organizational goals or objectives regarding internationalisation and the practices and behaviour of the faculty, when the organization lacks discretionary resources to devote to these aims (Dewey and Duff 2009). Similar dynamics are likely to occur in PRO. When considering the typology shown in Table 1 it is important to realise that between the organizations that fall under the different ideal types there are considerable differences in both the relative size of their research budget and the amount of autonomy they have in deciding how to use it.

A second condition related to the external autonomy refers to the "clients" or "users" of their research activities. If the clients are firms that contribute with significant resources to the functioning of the research institute, and moreover there is an internal hierarchical managerial direction, it is very likely that the institute will "follow" the firms on which it depends, also if it implies internationalising. The notion of "clients" is, however, rather alien in the knowledge production of many PRO. Moreover many of them (particularly MOC and PRC) still receive a large share of their funding through 
block grants earmarked for the maintenance of infrastructure and the payment of the salaries of their permanent researchers, who have civil servant status. In this context, capacities for strategic actorhood at the organizational level are likely to be very limited, if not marginal. As a general rule, those PRO that are fundamentally financed through project-based funding and have a small proportion of their funding portfolio coming directly from the state, face greater incentives to internationalise (fund raising or fund applications). Overall, it seems that access to additional discretionary resources and access to users and clients are catalysts of strategic internationalisation. RTOs seem to combine both.

A third condition affecting external autonomy refers to the funding regime predominant in the system. About 85 per cent of public research investment still goes only to national endeavours ${ }^{9}$ and the research space in which PROs operate thus maintains a strong national dimension, especially as regards block funding. However, over the past decades European funding sources have become increasingly important: and the share of transnational public R\&D programs in the total competitively allocated public project funding is significant. PROs receive a considerable share of these resources. For example, in an interim evaluation of the Framework Programme, it was shown that the CNRS, the Fraunhofer Gesellschaft, the CEA ${ }^{10}$ and the MPG were the largest recipients of FP7 funding (Annerberg et al. 2010). Changes in the funding regimes and the emergence of European level funding sources are likely to have affected the various types of PRO in different ways. Depending on their specific sector or field, but also the level of control they have over their own budgets and their size, some types of PROs are better equipped to compete, collaborate and contract with other (including foreign) actors and engage in strategic interaction with national and European policy makers to negotiate and influence the outcomes of this process of Europeanisation.

Many PRC (mostly academic research institutes and science academies) have internationalised as a way to access resources (funding and human capital) rather than as a way to access markets or clients. These PRC were searching for research complementarities (and capacities they lacked) through specific collaborations and strategic alliances-- to increase their ability to acquire resources from domestic and

\footnotetext{
${ }^{9}$ http://www.esf.org/about-esf.html.

${ }^{10}$ The CEA is the French Alternative Energies and Atomic Energy Commission.
} 
international sources. For example, the Spanish CSIC, the French CNRS and German MPG (all basic academic science oriented centers) are increasingly open to "inward internationalisation" focused on recruitment and co-authorship, and outward internationalisation focused on getting funding from abroad and getting access to foreign physical and human capital to search for complementarities. Most of the initiatives have been developed from below. However, if organizations grow in a rich environment (in terms of funding) they may also make decisions to develop strategic alliances and even to establish joint research facilities or funding their own networks in third countries. Examples include the joint units established by the German MPG and the French CNRS in both European and third countries (for example, China, India, and Argentina) (Jonkers and Cruz-Castro 2010). In these types of PROs, organizational slack (either related to funding or staff) will create more propensities for internationalization; budgetary reductions on the other hand will change the priorities: for example, in the context of the financial crisis, the Spanish CSIC, will mainly focus on actions involving a low level of consumption of local resources, such as opening up the recruitment or searching for funding.

In general, PRO internationalisation strategies are likely to be stronger if there is some organizational slack coupled with the potential for discretionary allocation of resources.

Most of the internationalisation activities in PRO have a limited link with entry in "foreign markets" (or direct investments, allocation of owned resources in classical terms of foreign direct investments). For a PRO to access markets beyond the national environment means basically to recruit, to sell knowledge and services, and to be funded internationally, as well as to associate with foreign partners. However there is a type of PRO (the RTO) in which we do find that sometimes access to foreign markets and following customers may be a relevant driver for internationalisation, for example the case of the Fraunhofer Gesellschaft in various Asian and American countries (supported by the German Government) or Tecnalia in Scotland (following Iberdrola).

Apart from the establishment of alliances and other organizational level collaborations, there are even examples of the set-up of foreign subsidiaries, crossborder mergers or investments to obtain stakes in foreign RTO. An example of the latter the acquisition by the Netherlands Organisation for Applied Scientific Research (TNO) of 10 per cent of an Austrian RTO, the Joanneum Research. The motivation for this 
action was that the greater autonomy over resources from non-national actors gave TNO a greater potentiality to further engage strategically in a process of internationalisation. It aimed to increase its market links and facilitate cooperation in different Member States (EC 2007). ${ }^{11}$ Furthermore, four RTOs - the TNO, the Technical Research Centre of Finland (VTT), the Joanneum Research and Tecnalia also established a Joint Institute for Innovation Policy (JIIP), presumably to become a more attractive partner for international clients.

In some countries, MOC have become RTO as a result of the evolution and reforms implemented by governments granting them more autonomy and independence; for example, TNO used to be a traditional mission-oriented research organization but configured as an umbrella organization; in other countries the RTO have evolved from independent private entities or associations into RTO.

The Mission oriented centers (MOCs), such as the Spanish National Institute for Agronomic Research (INIA), the French National Institute for Agricultural Research (INRA), and the Netherlands Organization for Agricultural Research (DLO), are by definition neither multi-sectorial nor multi-technological. They develop applied research linked to users or sectors, meaning that they have strong links with local sectors and they tend to function as local knowledge providers. However, some of them may also be quite active internationally. INRA, for example, is an active player at the European level and engages in organizational level collaboration with partners in other European countries. It has, for example, two joint laboratories in China and a permanent representative office together with the French CIRAD (Agricultural Research for Development). Wageningen UR was formed out of a merger of a research university and a former MOC (DLO) and is international in its orientation at the organizational and subunit level. Rothamsted Research, an agricultural experimental station and research centre in the UK, is also international in nature and, for example, established a joint laboratory in China.

The group of IRI (basic knowledge with links with users; Pasteur quadrant model), such as the Spanish CNIO (Spanish National Cancer Research Centre), the Dutch NKI (Netherlands Cancer Institute) or the French Institute Pasteur, has high levels of external autonomy in comparison with PRC and MOC; by design, they show

\footnotetext{
${ }^{11}$ In December 2014, TNO sold its share to the regional government of Kärnten - due to a changing financial situation. http://kaernten.orf.at/news/stories/2684715/
} 
high levels of internationalisation in terms of recruitment, funding and international collaboration. As a result of the openness emerging from frontier science the IRI will increase their active involvement in international activities to increase their funding and in that way reduce their dependence on local sources.

In sum, autonomy-related conditions to engage strategically with their environments with respect to the process of Europeanisation/internationalisation include, among others, funding structures, rules regarding employment and high degrees of management autonomy that prevent locking-in institutes at the national level. Conversely, a strong dependence on the state and little discretionary authority over resources limit the capability of PRO to establish new internationalisation goals, unless the state directly allocates new resources (Whitley 2010). There are considerable variations between the levels of external autonomy across European PRO even for those that are classified under the same 'ideal type'. As shown in Table 1, in MOC this level of external autonomy is expected to be low. However it is not high in the case of some PRC either, because governments tend to keep a considerable degree of control over employment and funding. When considering block funding it is important to realise that PRO leadership tends to have limited discretionary authority over it, since most of these resources are earmarked for salary and infrastructure costs. IRI and RTO usually have more flexibility to determine employment conditions, resource allocation and organizational structures. This greater autonomy gives these types of PRO, which often operate as non-profit foundations, more room for strategic manoeuvre. The emergence of new patrons in the form of European level research funders can provide all PRO opportunities to lessen their dependency on the national/regional states - provided they have the political/organizational autonomy to do so.

Turning to the dimension of internal authority, PRC share with universities some strong barriers to developing competences on internationalisation on the basis of their (limited) authoritative internal coordination capacities and control of the research activities within their organization (Whitley 2010). In research organizations where the distribution of authority is decentralised and researchers are very autonomous, PRO may find it harder to develop strategic approaches towards internationalisation. As a result, the Europeanisation of this type of PRO will tend to be the aggregate of the individual preferences and orientations of its researchers. Additionally, in these organizations, we can expect Europeanisation to be driven to a large extent by external 
factors including changing scientific dynamics, the availability of European funding sources, greater mobility and communication possibilities. The PRO can provide stimulation to its researchers to engage in these activities through material, institutional and discursive actions.

The capacity of many PRC to direct research activities to international arenas is limited by their need to rely on collective judgment to evaluate possible options. This echoes the analysis of Van der Meulen (2002) who argues that the Europeanisation of universities mainly takes place at the level of organizational sub-units. Similar arguments can be found in the analysis of Edler et al (2012) and Whitley (in Edler et al. 2012); in PRO in which scientific logics and scientific dynamics are particularly important (PRC and IRI) strategic decisions with respect to internationalisation tend to be made or at least shaped at lower levels of research organizations (schools, departments, units or even individual researchers). At this level the interaction between the scientific field and the research space (Nedeva 2013) is more pronounced than at higher levels because of the differences in the dynamics between different scientific fields.

PRO that have a greater degree of internal centralisation in the form of managerial leadership (for example, many RTO and MOC) may be able to engage more strategically with their changing external environment by making decisions that are binding upon their staff members and commit resources to internationalisation objectives. Combining the two attributes we could argue that PRO that are characterised by a lack of both external autonomy and internal authority are heavily dependent on their tutelary public authorities. This was traditionally the case for many MOC, though over time this dependency has been decreasing for some organizations. Even in the instance of a reduction in the availability of public funding, such organizations are less likely to supplement their finances by competing for European/international funding. Over the years, however, many PROs have sought or have been forced to accept an increase in autonomy from their ministries. Some preliminary evidence was found that MOCs that do have a higher degree of autonomy do engage in strategic internationalisation activities at the organizational level (Arnold et al. 2010). Additionally, some policy led developments, as in the case of metrology under article 185 of the Treaty on the Functioning of the European Union (ex article 169 of the Treaty establishing the European Community) which enables the EU to participate in 
research programmes undertaken jointly by Member States, can also promote European integration (Barker et al. 2012).

PRO with a combination of limited autonomy and low levels of internal authority have difficulties engaging strategically with their changing environment through internationalisation. As a consequence, while they may profess internationalisation as a strategic goal at the discursive level, this is not always translated in structural changes within the organization. One may wonder whether internationalisation processes are sustainable without an organizational strategy or whether this type of organizations will continue to adapt mainly passively, through bottom-up processes - processes which are likely to occur to a more limited extent than in organizations in which real changes in both strategies and structures with regard to internationalisation are made. PRO with higher levels of organizational autonomy (and resources), possibly in combination with higher levels of internal authority, have a higher potential for strategic internationalisation and are therefore expected to have changed their respective strategies and structures and to be more successful in directing or facilitating their researchers to engage with their changing environment.

\section{CONCLUDING REMARKS}

Organizational differences regarding external autonomy and internal authority generate variations in the capabilities of PRO to internationalise in a more adaptive or strategic way. From what came out of our analysis there are some initiatives, linked to European research policies that could shape and help increase the level of Europeanisation (internationalisation) of PRO at the organizational level. Considering that we are dealing with structural attributes of national institutions, organizational change can only occur either as an effect of incentives or from the application of rules; the history of European research policy has shown that funding incentives are a necessary but not sufficient condition to trigger institutional transformation.

The integration of the distributive stream of EU research policy with a regulatory stream seems necessary for advancing towards a European science space, mainly with the rationale of reducing the barriers for developing international strategies and structures at the PRO level. 
We have identified that the level of resources, its sources, and destination, as well as its control and management, are determinants of the opportunities for promoting strategic Europeanisation. Therefore, more European resources and "tuned instruments" could help the PRO (and other actors) to become more engaged in the European arena (versus the local ones).

We have also argued that the limited organizational autonomy and managerial discretion of most PRO are (especially in the context of limited resources) major constraints for PRO to become seriously engaged in strategic Europeanisation. Thus, effective changes promoted at national level to enhance organizational autonomy and managerial discretion (in the context of fair assessment of accomplishments related to their missions and responsibilities) of the PRO would be needed to advance strategic Europeanisation.

In the current context, also in line with the approach of EU policy associated with the ERA and the Open Method of Coordination (see also chapter 5 of this volume) and implementation measures in research policy (Kaiser and Prange-Gstoehl 2010) it would be sound to attempt to reduce national regulations inhibiting Europeanisation as a strategic organizational development, or replace them with rules, perhaps voluntarily agreed as a code of good practices, set up at European level. This would entail changing some employment, promotion, and evaluation systems linked to national models of civil service which structurally inhibit strategic Europeanisation and actors' playing in the global arena.

We cannot conclude our final remarks without setting some note of caution on the possible outcomes of the strategic Europeanisation process. The PSR in Europe will become more stratified, with more actors playing in the international/European arena of research even if they still remain mainly funded by national sources. At the same time, some PROs are likely to remain national or local players only.

Additionally, it could also be the case that a process of internal differentiation occurs at PRO level, especially if the capabilities of managers and their discretion over the use of resources remain limited, with sub-units displaying high levels of Europeanisation and internationalization (through bottom-up processes), existing alongside other units mainly engaged in local activities. The consequences of both kinds of dualisation dynamics could be an interesting topic for further analysis. 


\section{REFERENCES}

Annerberg, R., Begg, I., Acheson, H., Borras, S., Hallen, A., Maimets, T., Mustonen, R., Raffler, H., Swings, JP., Ylihonko, K., Interim Evaluation of the Seventh Framework Programme Report of the Expert Group, Report prepared for the European Commission, DG Research, European Research Area, 7th Framework programme, Luxembourg: publication office of the European Union, http://ec.europa.eu/research/evaluations/pdf/archive/other_reports studies and docume nts/fp7 interim_evaluation_expert_group_report.pdf [Accessed on August 21, 2013].

Arnold, E., K. Barker and S. Slipersæter (2010), Research Institutes in the ERA, Technopolis Group, http://ec.europa.eu/research/era/docs/en/research-institutes-in-theera.pdf [Accessed on August 17, 2015].

Barker, K.E., D. Cox and T. Sveinsdottir (2012), 'Reshaping European metrology research - the role of national research managers', $R \& D$ Management 42 (2), 170-80.

Banchoff, T. (2002), 'Institutions, Inertia and European Research Policy', Journal of Common Market Studies, 40 (1), 1-21.

Bartell, M. (2003), 'Internationalization of universities: A university culture-based framework', Higher Education, 45 (1), 43-70.

Berger, M. and R. Hofer (2011), 'The internationalisation of research technology organisations (RTO) - Conceptual Notions and Illustrative Examples from European RTOs in China', Science Technology Society, 16 (1), 99-122.

Boden, R., D. Cox, and M. Nedeva (2006), 'The appliance of science? - New public management and strategic change', Technology Analysis and Strategic Management, 18 (2), 125-241.

Boden, R., D. Cox, M. Nedeva, and K. Barker (2004), Scrutinising science: The changing UK government of science, Houndmills, New York: Palgrave-Macmillan.

Boekholdt, P., J. Edler, P. Cunningham, and K. Flanagan (2009), Drivers of international collaboration in research, final report. Report prepared for the European Commission, DG Research, international cooperation, Luxembourg: Publications Office of the European Union.

Bozeman, B., J.S. Dietz and M. Gaughan (2001), 'Scientific and technical human capital: an alternative model for research evaluation', International Journal of Technology Management, 22 (7/8).

Chou, M.H. (2012), 'Constructing an internal market for research through sectoral and lateral strategies: layering, the European Commission and the fifth freedom', Journal of European Public Policy, 19 (7), 1052-70.

Cox, D., P. Gummett, and K. Barker (eds.) (2001), Government laboratories. Transition and Transformation, Amsterdam: IOS Press.

Crow, M.M., and B. Bozeman (1998), Limited by design. R\&D Laboratories in the US National Innovation System, New York: Columbia University Press.

Dewey, P and S. Duff (2009), 'Reason before Passion: Faculty Views on Internationalization in Higher Education', Higher Education, 58 (4), 491-504. 
Drori, G.S., J.W. Meyer, F.O. Ramirez, and E. Schofer (2003), Science in the Modern World Polity. Institutionalizations and Globalization. Stanford: Stanford University Press.

Ebersberger, B. and J. Edler (2009), 'Internationalization of Public Research Organizations. Context, Strategies and Effects', Atlanta Conference on Science and Innovation Policy 2009, https://smartech.gatech.edu/handle/1853/32320.

Edler, J. (2003), 'Change in European R\&D Policy as a Complex Consensus-building Process', in J. Edler, S. Kuhlmann, and M. Behrens (eds.), Changing Governance of Research and Technology Policy: The European Research Area, Cheltenham, UK and Northampton, MA, USA: Edward Elgar, 98-132.

Edler, J., D. Frischer, M. Glanz, and M. Stampfer (2012), 'The impact of the ERC on universities and public research organizations', http://www.eurecia-erc.net/wpcontent/upLoads/EURECIA-ImpactOnResearchOrganisations.pdf. [Accessed on August 21, 2013].

Edler, J., D. Frischer, M. Glanz, and M. Stampfer (2014), 'Funding individuals-Changing Organisations: The impact of the ERC on Universities', in Whitley and Gläser (eds), Organizational transformation and Scientific Change: The Impact of Institutional Restructuring on Universities and Intellectual Innovation (Serie Research in the Sociology of Organizations 42), Bingley: Emerald Group Publishing Limited: 77-109.

European Commission (2007), Commission staff working document accompanying the Green Paper 'The European Research Area: New Perspectives', COM (2007)161, http://ec.europa.eu/research/era/pdf/era_swp_final.pdf. [Accessed on August 17, 2015].

European Commission (2011), Innovation Union Competitiveness Report 2011. Brussels: European Commission.

Gassmann, O. and M. von Zedtwitz (1999), 'New Concepts and Trends in International R\&D Organization', Research Policy, 28 (2-3), 231-50.

Guzzetti, L. (1995), A Brief History of European Union Research Policy, Office for Official Publications of the European Communities.

Hicks, D. (2012), 'Performance-based university research funding systems', Research Policy, 41 (2), 251-61.

Jonkers, K. and L. Cruz-Castro (2010), 'The Internationalisation of Public Sector Research through International Joint Laboratories', Science and Public Policy, 37 (8), 559-70.

Kaiser, R., and H. Prange-Gstoehl (2010), 'A paradigm shift in European R\&D policy? The EU Budget review and the economic crisis', Science and Public Policy, 37, 25365.

Katz, J.S. and B.R. Martin (1997), 'What is research collaboration', Research Policy 26 (1), $1-18$

Krücken, G. and F. Meier (2006), 'Turning the university into an organizational actor', in Gili, S.D., J.W. Meyer and H. Hwang, (eds.) Globalization and Organization. World Society and Organizational Change, Oxford: Oxford University Press, 241-57.

Langfeldt, L., H. Godø, A. Gornitzka, and A. Kaloudis (2012), 'Integration modes in EU research: Centrifugality versus coordination of national research policies', Science and Public Policy, 39 (1), 88-98. 
Lepori, B., P. van den Besselaar, M. Dinges, B. Poti, E. Reale, S. Slipersaeter, J. Theves and B. van der Meulen (2007), 'Comparing the Evolution of National Research Policies: What Patterns of Change', Science and Public Policy 34 (6), 372-88.

Malhotra, N. and C.R. Hinings (2010), 'An organizational model for understanding internationalization processes', Journal of International Business Studies, 41 (2), 33049.

March, J.G. (1994), A Premier on Decision-Making, New York: Free Press.

Martinez, C., J. Azagra-Caro and S. Maraut (2013), 'Academic inventors and scientific impact: The institutionalization of research in Pasteur's Quadrant', Industry and Innovation 20(5): 438-455.

McGuinness, N. and C. O'Carrol (2010), 'Benchmarking Europe's Lab Benches: How Successful has the OMC been in research policy', Journal of Common Market Studies, 48 (2), 293-318.

Nedeva, M., D. Braun, J. Edler, D. Frischer, M. Glanz, J. Glaser, P. Laredo, G. Laudel, T. Luukkonen, M. Stampfer, D. Thomas, and R. Whitley (2012), Understanding and assessing the impact and outcomes of the ERC and its Funding Schemes (EURECIA), Final synthesis Report, Brussels: ERC. [Accessed on August 21, 2013].

Nedeva, M., and M. Stampfer (2012), 'From "Science in Europe" to "European Science"', Science, 336 (6084), 982-3.

Nedeva, M. (2013), 'Between the global and the national: Organising European science', Research Policy, 42 (1), 220-30.

OECD (2010), Performance based Funding for public research in Tertiary Education Institutions, Paris: OECD.

OECD (2011a), Public Research institutions. Mapping Sector trends. Paris: OECD.

OECD (2011b), Public Sector Research Funding. Policy brief. The Innovation Policy Platform. (By L. Cruz-Castro, M. Bleda, G.E. Derrick, K. Jonkers, C. Martinez and L. Sanz-Menendez).

https://www.innovationpolicyplatform.org/sites/default/files/Public\%20Sector\%20Rese arch\%20Funding_0_0.pdf [Accessed on August 17, 2015].

OECD (2011c), Public Research Organisations. Policy brief. The Innovation Policy Platform. (By L. Sanz-Menendez, L. Cruz-Castro, K. Jonkers, G.E. Derrick, M. Bleda and C. Martínez).

https://www.innovationpolicyplatform.org/sites/default/files/Public\%20Research\%20Or ganisations 0 0.pdf [Accessed on August 17, 2015].

Olsen, J.P. (2002), 'The many faces of Europeanization', Journal of Common Market Studies, 40 (5), 921-52.

Paradeise, C., E. Reale, I. Bleiklei, and E. Ferlie (eds.) (2009), University Governance: Western European Comparative Perspective, Dordrecht: Springer.

Primeri, E., and E. Reale (2012), 'How Europe Shapes Academic Research: insights from participation in European Framework Programmes', European Journal of Education, 47(1), 104-21.

Sanz Menéndez, L. and S. Borras (2001), 'Explaining changes and continuity in EU technology policy: the politics of ideas', in S. Dresner and N. Gilbert (eds.), Changing European Research System, Aldershot: Ashgate Press, pp. 28-51. 
Sanz-Menéndez, L. and L. Cruz-Castro (2003), 'Coping with environmental pressures: Public research organizations responses to funding crisis', Research Policy, 32 (8), 1293-308.

Senker, J. (2000), 'Introduction to a special issue on changing organization and structure of European public sector research systems', Science and Public Policy, 27 (6), 394-6.

Slipersaeter, S., and D.W. Aksnes (2008), 'The many ways of internationalization, Patterns of R\&D funding and collaboration', in Gornitzka, Å. and Langfeldt, L. (eds.), Borderless Knowledge, Understanding the "New" Internationalisation of Research and Higher Education in Norway, Dordrecht: Springer.

Stokes, Donald E. (1997), Pasteur's Quadrant. Basic Science and Technological Innovation, Washington D.C.: The Brookings Institution.

Stromquist, N.P. (2007), 'Internationalization as a response to globalization: Radical shifts in university environments', Higher education, 53 (1), 81-105.

Van den Besselaar, P., A. Inzelt, E. Reale, E. De Turckheim, and V. Vercesi (2012), Indicators of Internationalisation for Research Institutions: a new approach, A report by the ESF Member Organisation Forum on Evaluation: Indicators of Internationalisation, http://www.fteval.at/upload/Indicators_of_Internationalisation_for_Research_Institution s.pdf. [Accessed on August 17, 2015].

Van der Meulen, B. (2002), 'Europeanization of Research and the Role of Universities: An Organizational-Cultural Perspective', Innovation: The European Journal of Social Science Research, 15 (4), 341-55.

Von Zedtwitz, M. and O. Gassmann (2002), 'Market versus Technology Drive in R\&D Internationalization: Four different patterns of managing research and development', Research Policy, 31 (4), 569-88.

Whitley, R. (2003), 'Competition and Pluralism in the Public Sciences: The Impact of Institutional Frameworks on the Organisation of Academic Science', Research Policy 32 (6), 1015-29.

Whitley, R. (2008), 'Universities as strategic actors', in L. Engwall and D.L. Weaire (eds.), The University in the Market, London: Portland Press, 22-37.

Whitley, R. (2010), 'Reconfiguring Public Science: The Impact of Governance Changes on Authority and Innovation in Public Science Systems', in R. Whitley, J. Gläser and L. Engwall (eds.), Reconfiguring Knowledge Production, Oxford: Oxford University Press, 3-47. 